\title{
Influence of Waste Materials Containing Tungsten on Melting and Crystallization of Glass-ceramics
}

\author{
Shaomin Lin, Bo Wang, Guishen Liu, Liqing Li, Xiaodong Hou \\ ${ }^{1}$ Research Institute of Environmental Chemistry and Technology, Hanshan Normal University, Chaozhou, China \\ ${ }^{2}$ National Center of Supervision and Inspection for Ceramic, Sanitary and Plumbing Fixture, \\ Chaozhou Supervision Testing Institute of Quality and Metrology, Chaozhou, China \\ Email: 1sm678@126.com
}

Received 2012

\begin{abstract}
Influences of waste materials containing tungsten on melting and crystallization of glass-ceramics are discussed in this article. High temperature melting, nucleation and crystallization of glass-ceramics were explored by means of DTA, XRD and SEM. The high temperature melting performance of glass-ceramics ingredients can be effectively improved by mixing the right amount of waste materials containing tungsten. But the additive amount should be properly controlled, the mixing content of waste materials containing tungsten should be a range of $0.5 \sim 2.0 \%$. In the experiment of glass-ceramics ingredients system, the molten softening temperature of base glass powder reduced about $20^{\circ} \mathrm{C}$ by adding $1 \%$ waste materials containing tungsten, and the nucleation temperature reduced about $15^{\circ} \mathrm{C}$. The nucleation and crystallization performance of glass-ceramics mineral crystals can be promoted by mixing the right amount of waste materials containing tungsten. That is helpful to improve the quality of glass-ceramics products.
\end{abstract}

Keywords: Waste Materials Containing Tungsten; Glass-Ceramics; Melting Performance; Nucleation and Crystallization

\section{Introduction}

Utilizing industrial wastes and tailings as main raw materials to manufacture glass-ceramics is of great significance for the sustainable development of industry, not only can effectively solve the pollution problem of industrial wastes, and can realize resource recycling [1,2]. But in China, the utilization rates of industrial wastes and tailings are much less than the developed countries. One important reason is that the industrial wastes are various and their chemical compositions and mineral structures are complex. Thus, the physical and chemical properties, composition and structure of industrial wastes must be researched before utilization as resource, in order to adjust the formula ingredients and the production process in time and avoid the adverse effects in actual production[3,4].

Chaozhou region is the important ceramics industry base in China, the ceramic production is very large. Ceramic production uses a lot of mineral resources, but also causes many industrial wastes, such as kaolin tailings, etc. The reasonable utilization of industrial wastes is the urgent need for the sustainable development of ceramic industry. Glass-ceramics were prepared with kaolin tailings and fly ash as principal raw materials by powder sintering method, and the influences of waste materials containing tungsten on melting and crystallization of glass-ceramics are discussed in this article.

\section{Materials and Methods}

\subsection{Materials}

Industrial materials: kaolin tailings, fly ash and waste materials containing tungsten.

The samples of kaolin tailings were collected from FT ceramics plant and sieved through 60 mesh standard sieve. The samples of fly ash were collected from DT power plant and sieved through 200 mesh standard sieve. The chemical compositions are shown in Table 1.

The samples of waste materials containing tungsten were collected from XL tungsten plant, which using ion exchange refining production process, and the tungsten content of waste materials is about $1.97 \%$.

\subsection{Methods}

Preparation of glass-ceramics ingredients: According to the chemical and mineral compositions of various waste materials, the right formula system was designed, and the experimental formula was shown in Table 2. The raw materials, such as kaolin tailings, fly ash, $\mathrm{CaO}, \mathrm{Na}_{2} \mathrm{CO}_{3}, \mathrm{BaCO}_{3}$ and $\mathrm{ZnO}$, were weighed according to the proportion of ingredients, and the waste materials containing tungsten with different contents were added respectively. Glass-ceramics ingredients were prepared after mixed and grinded.

Table 1. Chemical compositions of kaolin tailings and fly ash.

\begin{tabular}{ccccccccc}
\hline Sample & $\mathrm{SiO}_{2}$ & $\mathbf{A l}_{2} \mathbf{O}_{3}$ & $\mathbf{F e}_{2} \mathbf{O}_{3}$ & $\mathbf{C a O}$ & $\mathbf{M g O}$ & $\mathbf{K}_{2} \mathbf{O}$ & $\mathbf{N a}_{2} \mathbf{O}$ & Loss \\
\hline Kaolin tailings (\%) & 73.74 & 15.10 & 0.35 & 0.24 & 1.16 & 5.65 & 1.26 & 3.28 \\
Fly ash (\%) & 44.40 & 36.15 & 4.92 & 6.88 & 1.96 & 1.00 & 0.60 & 3.26
\end{tabular}

Table 2. Proportions of formula compositions.

\begin{tabular}{cccccc}
\hline $\begin{array}{c}\text { Kaolin tailings } \\
(\%)\end{array}$ & $\begin{array}{c}\text { Fly ash } \\
(\%)\end{array}$ & $\begin{array}{c}\mathrm{CaO} \\
(\%)\end{array}$ & $\begin{array}{c}\mathrm{Na}_{2} \mathrm{CO}_{3} \\
(\%)\end{array}$ & $\begin{array}{c}\mathrm{BaCO}_{3} \\
(\%)\end{array}$ & $\begin{array}{c}\mathrm{ZnO} \\
(\%)\end{array}$ \\
\hline 70.00 & 5.81 & 14.00 & 4.65 & 4.65 & 2.33 \\
\hline
\end{tabular}


2) Preparation of base glass powder: The glass-ceramics ingredients were filled in corundum crucibles and melted in high temperature furnace. After heating up to $1420^{\circ} \mathrm{C}$ with heating rate of $5 \sim 10^{\circ} \mathrm{C} / \mathrm{min}$, the samples were melted at $1420^{\circ} \mathrm{C}$ for 180 minutes, then were taken out for water-quenching heat treatment in high temperature melting state. The base glass powder of glass-ceramics was prepared after grinded and sieved through 20 mesh standard sieve.

4) Differential Thermal Analysis: The samples of base glass powder were analyzed by DTA (DTA, Model TA-50H), after grinded and sieved through 200 mesh standard sieve.

5) Preparation of glass-ceramics samples: The base glass powder was filled in corundum moulds and sintered in high temperature furnace. The glass-ceramics samples were prepared after the nucleation and crystallization in the appropriate thermal system. The nucleation temperature is in the range from $920^{\circ} \mathrm{C}$ to $980^{\circ} \mathrm{C}$, the crystallization temperature is in the range from $1130^{\circ} \mathrm{C}$ to $1190^{\circ} \mathrm{C}$.

6) Samples analysis: The surface microstructure of glass-ceramics samples was analyzed by SEM (SEM, Model JSM- 6360LA), after soaked in 4\% HF solution for 60 seconds and dried. The mineral crystal compositions of glass-ceramics samples were analyzed by XRD (XRD, Model D8 ADVANCE), after grinded and sieved through 200 mesh standard sieve.

\section{Results and Discussion}

\subsection{Influence of Waste Materials Containing Tungsten on High Temperature Melting Performance}

In order to research the influence of waste materials containing tungsten on high temperature melting performance of glassceramics ingredients, the raw materials were weighed according to the basic formula compositions. The waste materials containing tungsten were added respectively with $0 \%, 0.5 \%, 1 \%$, $2.5 \%$ and $5 \%$, and the samples of A0, A1, A2, A3 and A4 were prepared. A series samples were filled in the divided corundum moulds and melted in high temperature furnace at $1380^{\circ} \mathrm{C}$. Then the molten state of A series samples was observed after furnace cooling. The result is shown in Figure 1.

Figure 1 shows that A series samples are melted and vitrified. There are a number of bubbles in molten mass of sample $\mathrm{A} 0$, and the bubbles reduce gradually from A0 to A2. Although the bubbles in samples A3 and A4 also is less, but the molten mass color turned into dark brown gradually. That is because

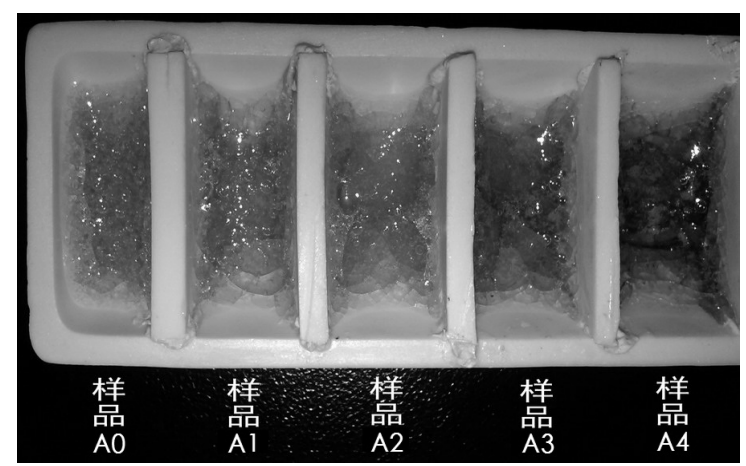

Figure 1. Comparison of the molten state of A series samples. the impurities in waste materials have adverse effect, when the additive amount is too high. The high temperature melting performance of glass-ceramics ingredients can be effectively improved by mixing the right amount of waste materials containing tungsten. But the additive amount should be properly controlled, in order to avoid the adverse effect of the impurities in waste materials. When the mixing content of waste materials containing tungsten is $1 \%$, the melting performance of ingredients system can be improved effectively.

\subsection{Influence of Waste Materials Containing Tungsten on Molten Softening Temperature and Nucleation Temperature}

In order to research the influence of waste materials containing tungsten on the molten crystallization process of base glass powder, the raw materials were weighed according to the basic formula compositions. Samples B0 and B1 were prepared, and sample B1 was added $1 \%$ waste materials containing tungsten. The samples of base glass powder of B series samples were analyzed by DTA, after melted, water-quenched, grinded and sieved through 200 mesh standard sieve. The results are shown in Figure 2.

Figure 2 shows the DTA curves of base glass powder of samples B0 and B1. The molten softening temperature of sample $\mathrm{B} 1$ is about $825^{\circ} \mathrm{C}$, and that of sample $\mathrm{B} 0$ is about $845^{\circ} \mathrm{C}$. The nucleation temperature of sample $\mathrm{B} 1$ is about $885^{\circ} \mathrm{C}$, and that of sample $\mathrm{B} 0$ is about $899^{\circ} \mathrm{C}$. After adding $1 \%$ waste materials containing tungsten, the molten softening temperature of base glass powder reduces about $20^{\circ} \mathrm{C}$ and the nucleation temperature reduces about $15^{\circ} \mathrm{C}$.

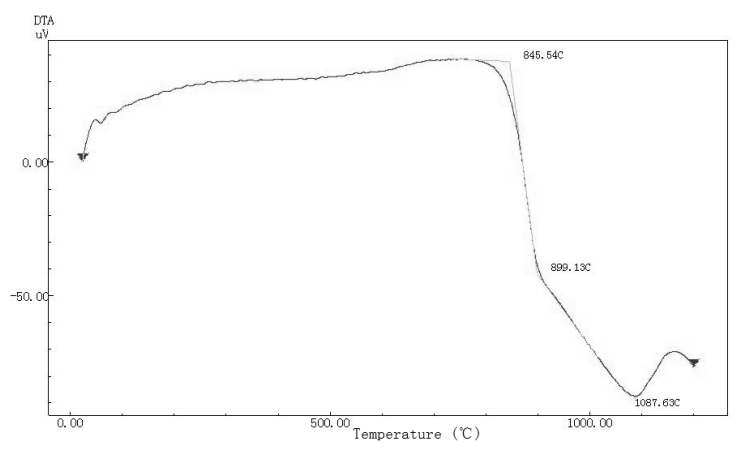

(a)

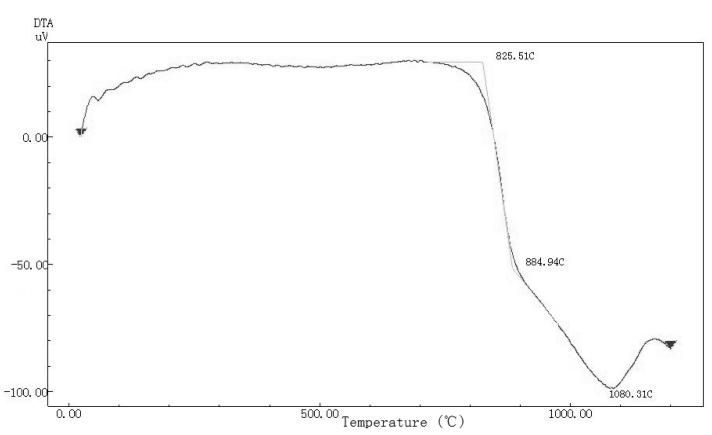

(b)

Figure 2. DTA curves of base glass powder of B series samples. (a) DTA curve of sample B0; (b) DTA curve of sample B1. 


\subsection{Influence of Waste Materials Containing Tungsten on Nucleation and Crystallization Behavior}

In order to research the influence of waste materials containing tungsten on the molten crystallization process of base glass powder, the glass-ceramics samples C0 and C1 were prepared after the nucleation crystallization processing, and sample C1 was added $1 \%$ waste materials containing tungsten. The surface microstructure of glass-ceramics samples C0 and C1 was analyzed by SEM. The results are shown in Figure 3.

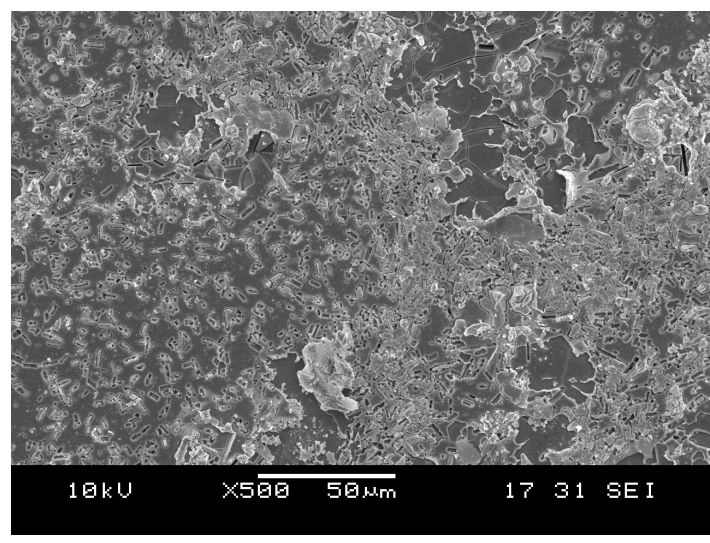

(a)

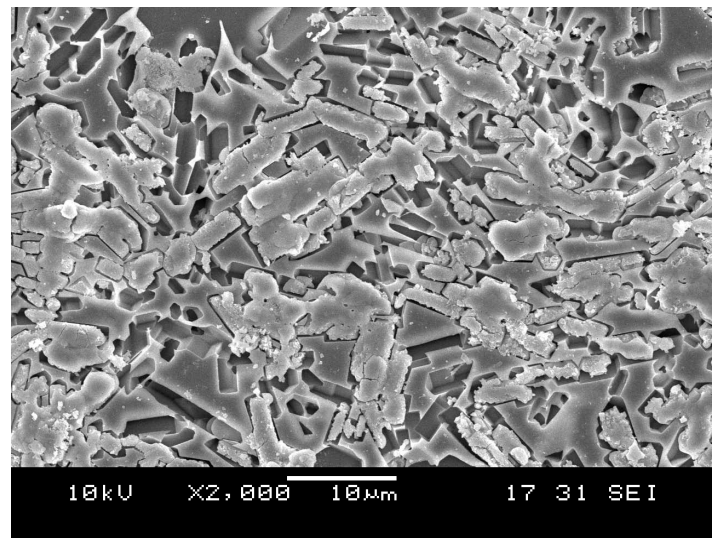

(b)

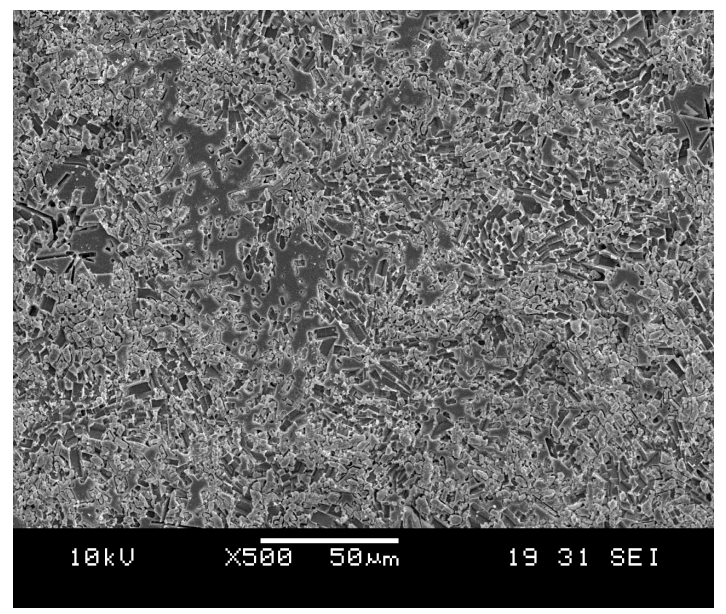

(c)

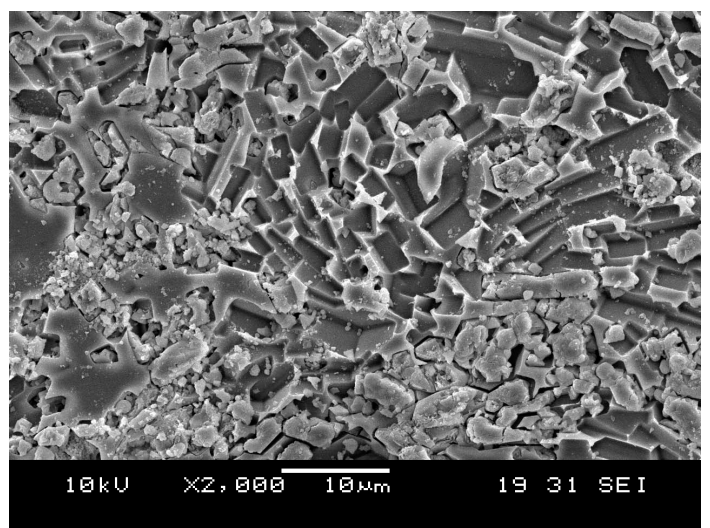

(d)

Figure 3. SEM photographs of glass-ceramics samples. (a) SEM photograph of sample C0 $(\times 500)$; (b) SEM photograph of sample C0 (×2000); (c) SEM photograph of sample C1 (×500); (d) SEM photograph of sample C1 $(\times 2000)$.

Figure 3 shows the SEM photographs of glass-ceramics samples C0 and C1. Compared to the image of sample C1, there are many undeveloped crystal nucleus existing in the image of sample C0. The crystal size of sample C1 is larger than that of sample C0, and the crystal structure is more compact. It is seen that the nucleation and crystallization behavior of glass-ceramics mineral crystals can be promoted by mixing the right amount of waste materials containing tungsten. That is helpful to improve the quality of glass-ceramics products.

The mineral crystal compositions of glass-ceramics samples C0 and C1 were analyzed by XRD, after grinded and sieved through 200 mesh standard sieve. The results are shown in Figure 4.

Figure 4 shows the XRD patterns of glass-ceramics samples $\mathrm{C} 0$ and $\mathrm{C} 1$. All the peaks were compared with JCPDS files. The $\mathrm{XRD}$ results show that the main crystalline phase of glass-ceramics samples $\mathrm{C} 0$ and $\mathrm{C} 1$ is $\beta$-wollastonite. Compared to the XRD pattern of sample $\mathrm{C} 0$, the characteristic peaks of glass- ceramics sample $\mathrm{C} 1$ have higher intensities at $23.2^{\circ}$, $25.4^{\circ}, 26.9^{\circ}$ and $30.0^{\circ}$. This once again shows that the nucleation and crystallization behavior of glass-ceramics mineral crystals can be promoted by mixing the right amount of waste materials containing tungsten.

\section{Conclusions}

Based on these results, three conclusions can be derived.

- The high temperature melting performance of glass-ceramics ingredients can be effectively improved by mixing the right amount of waste materials containing tungsten. But the additive amount should be properly controlled, in order to avoid the adverse effect of the impurities in waste materials. The mixing content of waste materials containing tungsten should be a range of $0.5 \sim 2.0 \%$.

- In the experiment of glass-ceramics ingredients system, the molten softening temperature of base glass powder reduced about $20^{\circ} \mathrm{C}$ by adding $1 \%$ waste materials containing tungsten, and the nucleation temperature reduced about $15^{\circ} \mathrm{C}$. That is of great significance for saving 
energy and reducing consumption in the actual production.

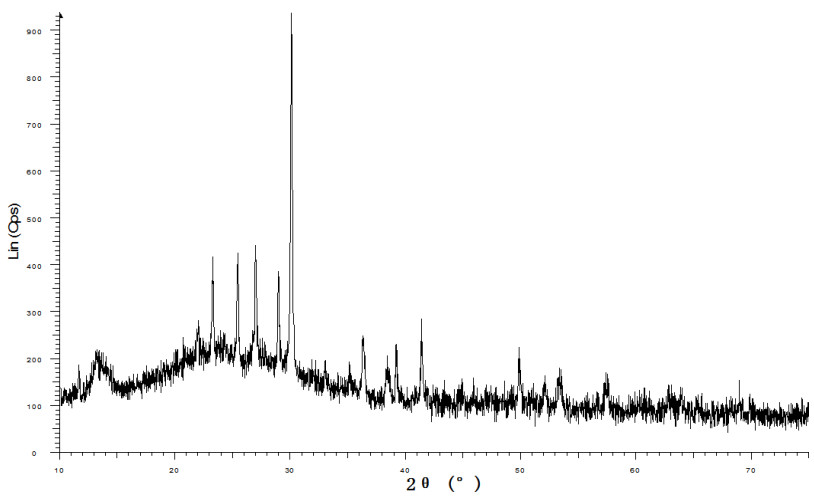

(a)

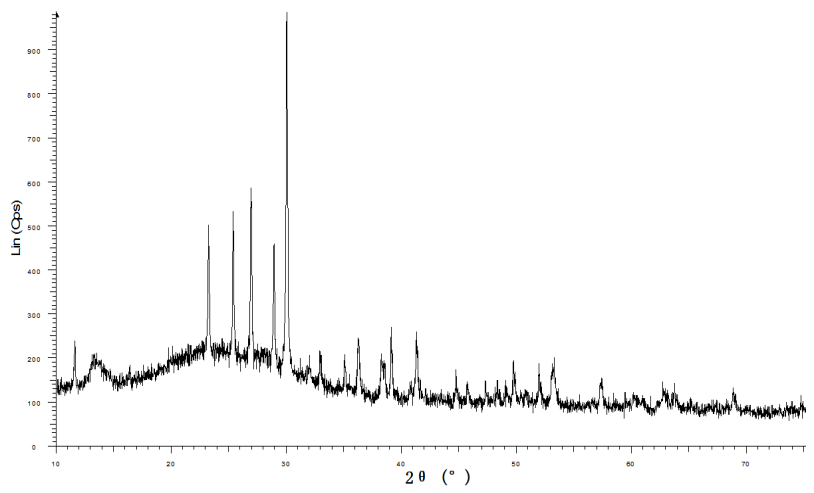

(b)

Figure 4. XRD patterns of glass-ceramics samples. (a) XRD pattern of sample C0; (b) XRD pattern of sample C1.

- The nucleation and crystallization performance of glassceramics mineral crystals can be promoted by mixing the right amount of waste materials containing tungsten. That is helpful to improve the quality of glass-ceramics products.

\section{Acknowledgements}

This work was supported by the National Natural Science Foundation of China (No. 21207027), the Science and Technology Project of General Administration of Quality Supervision (No. 2008QK277), the Natural Science Foundation of Guangdong Province (No. 8452104101001541), the Science and Technology Project of Chaozhou (No. 2008S21).

\section{REFERENCES}

[1] Peixin Zhang, Qiye Wen, Jianhong Liu, Qianling Zhang, and Xiangzhong Ren. Research progress in slag glass-ceramics [J]. Materials Review, 2003, 17(9): 46.

[2] Laiguang Hou, and Lingke Zeng. The current situation in comprehensive utilization of ceramic waste [J]. China Ceramic Industry, 2005, 12(4): 41-44.

[3] Liqing Li, Shuchao Zhang, Zhuangdun Lin, and Shaomin Lin. Influence of particle size distribution of ingredients on melting behavior of glass-ceramics [J]. Guangdong Chemical Industry, 2011, 38(8): 256-257.

[4] Bo Wang, Weipo Liu, Xiaodong Hou, and Shaomin Lin. Influence of ingredient components on melting behavior of glass-ceramics [J]. Guangdong Chemical Industry, 2011, 38(9): 226-227.

[5] Jinshu Cheng, Hong Li, and Liying Tang. Glass-ceramics(in Chinese). Beijing: Chemical Industry Press, 2006.

[6] Huidan Zeng, Zaide Deng, and Tingzhao Ying. Process principle and techniques for sintered glass-ceramics of wollastonite system [J]. Materials Review, 2000, 12(12): 26-28.

[7] Qin Jiang, Lei Lu, Wei Dong, Ying Zhao, and Lejun Zhang. Design for composition of multi-tailings slag glass ceramics and analysis of microstructure [J]. Multipurpose Utilization of Mineral Resources, 2006, (5): 31-34.

[8] Xiaoping Feng, Feng He, and Lihua Li. Research on crystallization behavior of CaO-Al2O3-SiO2 system glass-ceramics [J]. Journal of Wuhan University of Technology, 2001, (11): 22-24.

[9] Feng He, Qiantao Li, Jinshu Cheng, and Wangkai Hu. Influencing factors of the high temperature fluidity of $\mathrm{CaO}-\mathrm{Al} 2 \mathrm{O} 3-\mathrm{SiO} 2$ system sintering building glass-ceramic powder [J]. Bulletin of the Chinese Ceramic Society, 2004, (2): 93-95.

[10] M. Erol, S. Küçükbayrak, and A. Ersoy-Meriçboyu. Comparison of the properties of glass, glass-ceramic and ceramic materials produced from coal fly ash [J]. Journal of Hazardous Materials, 2008, 153(1): 418-425. 